\title{
Profile of PD-L1 mRNA Expression in Childhood Acute Leukemia
}

\author{
Muhammad Al Azhar ${ }^{1}$, Chainurridha ${ }^{1}$, Mururul Aisyi ${ }^{1,2}$
}

${ }^{1}$ Research and Development Department, National Cancer Center-Dharmais Cancer Hospital, Jakarta, Indonesia. ${ }^{2}$ Department of Paediatric Oncology, National Cancer Center-Dharmais Cancer Hospital, Jakarta, Indonesia.

\begin{abstract}
Background: Programmed Death Ligand 1 (PD-L1) expression was used to determine type of patients who respond to immunotherapy using immune checkpoint inhibitor in several solid malignancies. However, the role of PD-L1 in hematological malignancies is less explored. Therefore, we aim to investigate PD-L1 mRNA expression in childhood leukemia patients. Association between PD-L1 expression and clinicopathological features was also analyzed. Method: Blood samples of 17 childhood leukemia patients and 12 healthy individuals as control were used in this study. The samples were collected in Dharmais Cancer Hospital. Real time PCR was used to analyze PD-L1 expression with GAPDH as internal control. Result: PD-L1 mRNA expression is significantly lower in childhood leukemia patients (medians: 0.0012) compared to healthy individuals (medians: 0.0041) $(p=0.017)$. PD-L1 mRNA expressions were not correlated with age $(p=1.000)$, sex $(p=1.000)$, outcome $(p=1.000)$, type of leukemia $(p=1.000)$, hyperleukocytosis $(p=1.000)$, and syndrome down $(p=0.426)$. Conclusion: PD-L1 expression is lower in leukemia patients compared to healthy controls. PD-L1 expressions were not correlated with all clinicopathological features. Our result provides preliminary data of PD-L1 expression in Indonesian childhood leukemia patients.
\end{abstract}

Keywords: Childhood acute leukemia- PD-L1- immunotherapy- immune checkpoint inhibitor

Asian Pac J Cancer Biol, 6 (1), 37-41

\section{Introduction}

Leukemia is most common cancer in children with high mortality rate. Acute Lymphocytic Leukemia (ALL) and Acute Myelogenous Leukemia (AML) are 2 major types in pediatric leukemia [1]. Survival rates have improved in children with leukemia due to advances in treatment and supportive care [2]. However, rate of survival in childhood leukemia is still low in developing countries including in Indonesia [3]. Standard therapy for children with leukemia such as radiation and chemotherapy is not effective enough especially for those who faced resistant or recurrent cancers [4-5]. Patients with refractory, high-grade, recurrent or metastatic disease are still undergone extremely poor outcomes [2]. Therefore, novel therapy to treat childhood cancer is needed to improve patient's outcome.

Immunotherapy has emerged as an effective cancer treatment. CAR T cell therapy is one type of immunotherapy
Submission Date: 12/29/2020 Acceptance Date: 02/28/2021 that has shown promising result in treating childhood leukemia [4]. In solid tumor, immune checkpoint inhibitors such as anti-PD-1 and anti-PD-L1 have been approved by Food and Drug Administration (FDA) to treat several cancers such as melanoma and non-small cell lung cancer (NSCLC) [6]. Anti-PD-1/ PD-L1 treatment is type of immunotherapy that use monoclonal antibody (mAb) to inhibit the binding between programmed cell death-1 (PD-1) and programmed cell death ligand-1 (PD-L1) molecules in cancer patients [7-8]. Binding interaction between PD-1 and PD-L1 significantly down regulates T cell, thus causes tumor growth, promotes metastasis, and mediates immune suppression [8-10]. Therefore, blocking the engagement between these 2 molecules could enhance $\mathrm{T}$ cell responses and increase anti-tumor immunity [8-11].

In childhood cancer, pembrolizumab, $\mathrm{mAb}$ for PD-1 has been approved by FDA for the treatment of children

\footnotetext{
Corresponding Author:

Muhammad Al Azhar

Research and Development Department, National Cancer Center-Dharmais Cancer Hospital, Jakarta, Indonesia.

Email: m.al.azhar95@gmail.com
} 
with refractory classic Hodgkin Lymphoma (HL) [4]. In childhood leukemia, clinical trials using immune checkpoint inhibitors is currently on going [2]. A case report suggested that pediatric patient with multiple relapsed and refractory acute leukemia treated with combination of 5-azacytidine with immune checkpoint inhibitors (nivolumab and ipilimumab) is tolerated the therapy and showed improvement of symptoms [12]. It has been suggested that combinations of multiple immunotherapeutic and conventional therapy such as chemotherapy might improve pediatric cancer outcome [2-4]. Currently, there is an on-going clinical trial (NCT02813135) for combination of cyclophosphamide and nivolumab for the treatment of recurrent pediatric cancers [4].

PD-1 is an inhibitory receptor expressed on activated T cell. PD-L1 is a PD-1's ligand and commonly expressed on cancer cells and immune cells like $\mathrm{T}$ cell and $\mathrm{B}$ cell [8]. PD-L1 has 40-kDa size and categorized as type 1 trans-membrane cell surface glycoprotein and member of the B7 family of co-stimulatory molecules [2-9-13]. Studies have shown that expression of PD-L1 is associated with poor prognosis in several cancers such as melanoma and non-small cell lung cancer (NSCLC) including in pediatric cancer [2-4-14]. PD-L1 expression also has been correlated with response to anti PD-1/ PD-L1 therapy [14]. In fact, PD-L1 expression has been used to determine type of patients who respond to immune checkpoint inhibitors in several cancers [6]. FDA has approved the measurement of PD-L1 expression using immunohistochemistry as companion diagnostic for the treatment of NSCLC and melanoma using anti PD-1 [6-8].

However, in hematological malignancies especially in children, the role of PD-L1 is less explored. There are only a very few studies investigating PD-L1 expression in pediatric malignancies [15]. Besides, to the best of our knowledge, there is no study analyzing PD-L1 in childhood leukemia that has been done in Indonesia. Therefore, we aim to analyze PD-L1 mRNA expression in blood samples of childhood leukemia patients in Dharmais Cancer Hospital (National Cancer Center of Indonesia) and investigate the relationship between PD-L1 expression and clinicopathological features.

\section{Materials and Methods}

\section{Samples Collection}

We examined 17 blood samples of childhood leukemia patients which consist of 11 samples of ALL patients and 6 samples of AML patients. All cases have been confirmed in the Clinical Pathology Department, Dharmais Cancer Hospital. The 17 patients included 9 males and 8 females with an age ranging from 2 to 15 years (mean ages: $6.1 \pm 4.2$ ). As many as 12 healthy people were used as controls that were consisted of 6 males and 6 females. Blood samples were collected in ethylenediaminetetraacetic acid (EDTA) tubes then directly processed for RNA isolation. This study has been approved by Ethical Committee of Dharmais Cancer Hospital (code: 065/KEPK/VI/2020).

\section{Real time PCR analysis}

RNA molecule was extracted using Total RNA Blood/ Culture (Gene Aid). A maximum of 2000 ng of RNA was then reverse transcribed to cDNA using High Capacity cDNA Sythesis Kit (Applied Biosystem). Dilution to 100 ng was done to all cDNA samples. Diluted cDNA samples were then used in real time PCR analysis.

To avoid genomic DNA amplification, primers used in real time PCR were designed to span 2 different exons. For PD-L1, we used forward primer 5'-tgtgaaagtcaatgcccat-3', reverse primer 5'-tgtcagttcatgttcagaggt-3', and probe 5'-attttggttgtggatccagtc-3'. Glyceraldehyde-3-phosphate dehydrogenase (GAPDH) was used as internal control. For GAPDH, the forward primer, reverse primer, and probe were 5'-agcctcaagatcatcagcaa-3', 5'-actgtggtcatgagtccttc-3', and 5'-ctgcaccaccaactgcttag-3', respectively. All primers and probes were formulated and mixed by Applied Biosystem into Custom TaqMan Gene Expression Assay.

Single real time PCR reaction consisted of $10 \mu \mathrm{L}$ of TaqMan Gene Expression Master Mix (Applied Biosystem), $1 \mu \mathrm{L}$ of Custom TaqMan Gene Expression Assay (Applied Biosystem), $5 \mu \mathrm{L}$ of Nuclease Free Water, and $4 \mu \mathrm{L}$ of cDNA. We doubled the reaction for each sample. The thermal cycling condition for qPCR were: 2 minutes $\left(50^{\circ} \mathrm{C}\right)$ and 10 minutes $\left(95^{\circ} \mathrm{C}\right)$ hold stage, followed by 40 cycles of denaturation step at $95^{\circ} \mathrm{C}$ for 15 seconds, and annealing and extension step at $62^{\circ} \mathrm{C}$ for 1 minute. The reaction was performed in 7500 Fast Real-Time PCR System (Applied Biosystem).

Data was analyzed using $2^{-\Delta \Delta \mathrm{CT}}(\Delta \Delta \mathrm{CT}=\Delta \mathrm{CT}$ of each samples - average $\Delta \mathrm{CT}$ of healthy controls) to get the value of gene expression. We classified the level of gene expression as low or high expression by using average $\Delta \mathrm{CT}$ value of 12 healthy people as cut-off value. $\Delta \mathrm{CT}$ values of samples below average $\Delta \mathrm{CT}$ value of healthy controls were determined as high expression. Meanwhile, samples with $\Delta \mathrm{CT}$ values above average $\Delta \mathrm{CT}$ value of healthy controls were determined as low expression.

\section{Statistical analysis}

Statistical analysis was done using SPSS Statistics 22 statistical software (IBM Corporation). Fisher exact test was used to analyze the relationship between PD-L1 expression and clinicopathological characteristics. To analyze the comparison of PD-L1 expression in cancer and healthy control group, Man-Whitney test was performed. A value of $\mathrm{P}<0.05$ is considered statistically significant.

\section{Results}

The expression of PD-L1 in childhood leukemia patients PD-L1 expression in childhood leukemia patients is significantly lower compared to healthy controls. Median expression of PD-L1 in childhood leukemia is 0.0012 (ranges from 0.00005 to 0.077 ), while median expression of PD-L1 in healthy control group is 0.0041 (ranges from 0.0016 to 0.013$)(\mathrm{p}=0.017)$ (Figure 1). Gene expression in figure 1 is the result of $2^{-\Delta \Delta \mathrm{CT}}$ calculation method with median and error bar ( $95 \%$ confidence interval). 


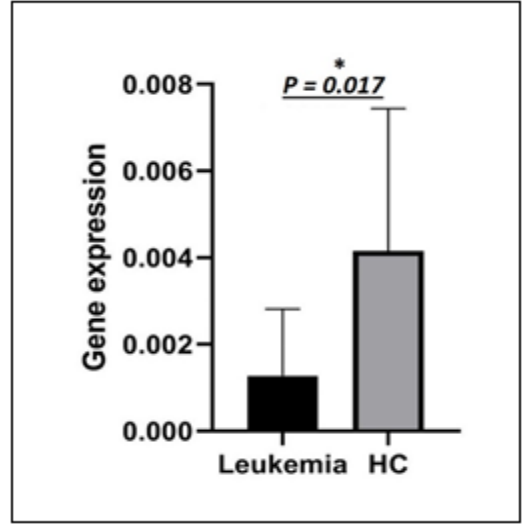

Figure 1. PD-L1 Gene Expression in Childhood Leukemia (Leukemia) and Healthy Controls (HC)

The association of PD-L1 expression and clinicopathological characteristic of childhood leukemia patients

From 17 samples analyzed, as many as 4 patients were categorized as high expression, while 13 patients were categorized as low expression. The expression of PD-L1 in childhood leukemia patients was not associated with all clinicopathological characteristics examined. The result showed that there was no significant relationship between PD-L1 mRNA expressions with age $(\mathrm{p}=1.000)$, sex $(p=1.000)$, outcome $(p=1.000)$, type of leukemia $(p=1.000)$, hyperleukocytosis $(p=1.000)$, and syndrome down $(\mathrm{p}=0.426)$ (Table 1).

\section{Discussion}

This study revealed that PD-L1 expression is significantly lower in childhood leukemia patients compared to healthy controls. We found a low frequency of PD-L1 high expression in pediatric leukemia. Only $23.5 \%$ (4/17) patients of childhood leukemia showed high PD-L1 expression. The same finding also found in previous reports in pediatric solid tumors. Positive PD-L1 expression was only found in 11 of 81 (14\%) of Wilms tumors [16] and only $13 \%$ of total 500 cases of pediatric tumors (including neuroblastoma, brain cancers, and sarcomas) [17]. Another study by Aoki et al. [18] showed positive PD-L1 expression only found in 1 sample of rhabdomyosarcoma out of 53 samples of pediatric solid tumors ( 8 extracranial malignant germ cell tumors, 18 neuroblastomas, 7 hepatoblastomas, 7 germinomas, 4 medulloblastomas, 4 renal tumors, 2 atypical teratoid/ rhabdoid tumor (AT/RT), and 3 rhabdomyosarcomas).

In human adults with leukemia, Chen et al. [19] described positive PD-L1 expressions were higher in monocyte leukemia (M5) patients than other type of leukemia (24\%), while Yang et al. [20] showed that PD-L1 mRNA expression were significantly higher in T-Acute lymphoblastic leukemia (T-ALL) compared to reactive hyperplasia. Meanwhile, in childhood leukemia, study by Feucht et al. [21] revealed inter-individual differences in PD-L1 expressions of childhood ALL. Variable PD-L1 expression patterns were found on patients' bone marrow blasts [21], suggested that PD-L1 expressions in childhood leukemia could be highly vary among different individuals. Moreover, Feucht et al. [21] revealed that high PD-L1 expression was mostly found in pediatric ALL patients who relapsed and not respond to Blinatumomab treatment.

It has been explained that PD-L1 gene abnormality such as change in PD-L1 gene copy number status might contribute to the increase of PD-L1 expression in cancer. Study by Inoue et al. [22] showed that tumor with PD-L1 genomic gains exhibit significantly higher PD-L1 expression compared to those without. Moreover, it has been shown that pediatric cancer seems to have lower gene mutation burden compared to cancer in adults [2-4]. In general, childhood cancers do not have high mutations rate [23]. Because of the low level of gene mutation burden in pediatric cancer, PD-L1 gene abnormality might not present in childhood leukemia, thus diminish

Table 1. Relationship between Clinicopathological Parameters and PD-L1 mRNA Expressions in Childhood Leukemia Patients

\begin{tabular}{|c|c|c|c|c|}
\hline Parameter & & $\begin{array}{c}\text { Low expression } \\
\mathrm{n}(\%)\end{array}$ & $\begin{array}{c}\text { High expression } \\
\mathrm{n}(\%)\end{array}$ & $\mathrm{p}$-value \\
\hline \multirow[t]{2}{*}{ Age } & $\leq 10$ & $11(78.6)$ & $3(21.4)$ & 1 \\
\hline & $>10$ & $2(66.7)$ & $1(33.3)$ & \\
\hline \multirow[t]{2}{*}{ Sex } & Male & $7(77.8)$ & $2(22.2)$ & 1 \\
\hline & Female & $6(75)$ & $2(25)$ & \\
\hline \multirow[t]{2}{*}{ Type of Leukemia } & ALL & $8(72.8)$ & $3(27.2)$ & 1 \\
\hline & AML & $5(83.3)$ & $1(16.7)$ & \\
\hline \multirow[t]{2}{*}{ Syndrome Down } & Yes & $1(50)$ & $1(50)$ & 0.426 \\
\hline & No & $12(80)$ & $3(20)$ & \\
\hline \multirow[t]{2}{*}{ Hyperleukocytosis } & Yes & $2(100)$ & $0(0)$ & 1 \\
\hline & No & $11(73.3)$ & $4(26.7)$ & \\
\hline \multirow[t]{2}{*}{ Outcome } & Life & $11(78.6)$ & $3(21.4)$ & 1 \\
\hline & Dead & $2(66.7)$ & $1(33.3)$ & \\
\hline
\end{tabular}

AML, Acute Myelogenous Leukemia; ALL, Acute Lymphocytic Leukemia 
one of the factors that is responsible for enhancing PD-L1 expression. This could explain why PD-L1 expression is lower in childhood leukemia. However, it should be confirmed with further study to analyze the correlation between PD-L1 gene abnormalities with PD-L1 expression in childhood leukemia.

This study also found that PD-L1 expression is not associated with all the clinicopathological parameters such as age, sex, outcomes, type of leukemia, hyperleukocytosis, and syndrome down. This might be due to the small sample size in our study. To find significant correlation, number of samples need to be added.

Pediatric cancer patients tend to exhibit poor response toward single immune checkpoint inhibitor therapy (anti-PD-1/ anti PD-L1) [4]. Low tumor mutation load might be one of the factors that cause poor response rate of anti-PD-1/ anti PD-L1 therapy in pediatric cancer [4]. In this study, we found most childhood leukemia patients have low PD-L1 expression. Since low PD-L1 expression is mostly related with poor clinical outcomes to anti-PD-1-directed therapy [24], this result might additionally explain why pediatric cancer patients seem to not give good response to single immune checkpoint inhibitor. It has been suggested that combination of therapy such as immune checkpoint inhibitor and chemotherapy might enhance response rate of pediatric cancer and improve survival [2-4]. However, the limitation of this study is very small sample size. To obtain more accurate data, more samples need to be added and comparison with immunohistochemistry of PD-L1 as gold standard to measure PD-L1 expression need to be done in the subsequent experiment.

In conclusion, PD-L1 expression seems to have low expression level in childhood leukemia. This might explain why single immune checkpoint inhibitor therapy did not show very good result in pediatric cancer patients. Besides, we also found, the expressions of PD-L1 were not correlated with all clinicopathological features. This result provides preliminary data of PD-L1 expression in Indonesian pediatric leukemia patients.

\section{Acknowledgements}

The authors wish to thank to Department of Research and Development, Dharmais Hospital-National Cancer Center for providing the funding and instrument used in the study.

\section{Competing of Interest}

The authors declare no conflict of interest.

\section{References}

1. Bernard S, Abdelsamad E, Johnson P, Chapman D, Parvathaneni M. Pediatric leukemia : Diagnosis to treatment - A review. Journal of Cancer Clinical trials. 2017;2(2):2-4.

2. Ring E, Gillespie G, Friedman G. Pediatric Malignancies [Internet]. Immune Checkpoint Inhibitors in Cancer. Elsevier Inc.: 193-204.
3. Haileamlak A. The Challenge of Childhood Cancer in Developing Countries. Ethiopian journal of health sciences. 2016;26(3):199-200.

4. Wedekind MF, Denton NL, Chen C, Cripe TP. Pediatric Cancer Immunotherapy: Opportunities and Challenges. Pediatric Drugs. 201806 12;20(5):395-408. https://doi. org/10.1007/s40272-018-0297-x

5. Ward E, DeSantis C, Robbins A, Kohler B, Jemal A. Childhood and adolescent cancer statistics, 2014. CA: A Cancer Journal for Clinicians. 201401 31;64(2):83-103. https://doi.org/10.3322/caac.21219

6. Koppel C, Schwellenbach H, Zielinski D, Eckstein S, Martin-Ortega M, D’Arrigo C, Schildhaus H, Rüschoff J, Jasani B. Optimization and validation of PD-L1 immunohistochemistry staining protocols using the antibody clone $28-8$ on different staining platforms. Modern Pathology. 201806 26;31(11):1630-1644. https://doi. org/10.1038/s41379-018-0071-1

7. Pardoll DM. The blockade of immune checkpoints in cancer immunotherapy. Nature Reviews Cancer. 201203 22;12(4):252-264. https://doi.org/10.1038/nrc3239

8. Topalian SL, Taube JM, Anders RA, Pardoll DM. Mechanismdriven biomarkers to guide immune checkpoint blockade in cancer therapy. Nature Reviews Cancer. 201604 15;16(5):275-287. https://doi.org/10.1038/nrc.2016.36

9. Dong H, Strome SE, Salomao DR, Tamura H, Hirano F, Flies DB, Roche PC, Lu J, Zhu G, Tamada K, Lennon VA, Celis E, Chen L. Tumor-associated B7-H1 promotes T-cell apoptosis: A potential mechanism of immune evasion. Nature Medicine. 200206 24;8(8):793-800. https://doi. org $/ 10.1038 / \mathrm{nm} 730$

10. Chen L, Han X. Anti-PD-1/PD-L1 therapy of human cancer: past, present, and future. Journal of Clinical Investigation. 201509 01;125(9):3384-3391. https://doi.org/10.1172/ jci80011

11. Iwai Y, Ishida M, Tanaka Y, Okazaki T, Honjo T, Minato N. Involvement of PD-L1 on tumor cells in the escape from host immune system and tumor immunotherapy by PD-L1 blockade. Proceedings of the National Academy of Sciences. 200209 06;99(19):12293-12297. https://doi.org/10.1073/ pnas. 192461099

12. Broglie L, Gershan J, Burke MJ. Checkpoint inhibition of PD-L1 and CTLA-4 in a child with refractory acute leukemia. International Journal of Hematologic Oncology. 2019 02;8(1):IJH10. https://doi.org/10.2217/ijh-2018-0009

13. Keir ME, Liang SC, Guleria I, Latchman YE, Qipo A, Albacker LA, Koulmanda M, Freeman GJ, Sayegh MH, Sharpe AH. Tissue expression of PD-L1 mediates peripheral T cell tolerance. Journal of Experimental Medicine. 200604 10;203(4):883-895. https://doi.org/10.1084/jem.20051776

14. Gibney GT, Weiner LM, Atkins MB. Predictive biomarkers for checkpoint inhibitor-based immunotherapy. The Lancet Oncology. 2016 Dec;17(12):e542-e551. https://doi. org/10.1016/s1470-2045(16)30406-5

15. Gabrych A, Pęksa R, Kunc M, Krawczyk M, IzyckaSwieszewska E, Biernat W, Bień E. The PD-L1/PD-1 axis expression on tumor-infiltrating immune cells and tumor cells in pediatric rhabdomyosarcoma. Pathology Research and Practice. 2019 Dec;215(12):152700. https:// doi.org/10.1016/j.prp.2019.152700

16. Routh JC, Ashley RA, Sebo TJ, Lohse CM, Husmann DA, Kramer SA, Kwon ED. B7-H1 Expression in Wilms Tumor: Correlation With Tumor Biology and Disease Recurrence. Journal of Urology. 2008 05;179(5):1954-1960. https://doi. org/10.1016/j.juro.2008.01.056

17. Saletta F, Vilain RE, Gupta AK, Nagabushan S, Yuksel A, Catchpoole D, Scolyer RA, Byrne JA, McCowage G. 
Programmed Death-Ligand 1 Expression in a Large Cohort of Pediatric Patients With Solid Tumor and Association With Clinicopathologic Features in Neuroblastoma. JCO Precision Oncology. 2017 Nov;(1):1-12. https://doi.org/10.1200/ po.16.00049

18. Aoki T, Hino M, Koh K, Kyushiki M, Kishimoto H, Arakawa Y, Hanada R, Kawashima H, Kurihara J, Shimojo N, Motohashi S. Low Frequency of Programmed Death Ligand 1 Expression in Pediatric Cancers. Pediatric Blood \& Cancer. 201605 02;63(8):1461-1464. https://doi.org/10.1002/ pbc. 26018

19. Chen X, Liu S, Wang L, Zhang W, Ji Y, Ma X. Clinical significance of B7-H1-PD-L1-expression in human acute leukemia. Cancer Biology \& Therapy. 2008 05;7(5):622-627. https://doi.org/10.4161/cbt.7.5.5689

20. Yang K, Xu J, Liu Q, Li J, Xi Y. Expression and significance of CD47, PD1 and PDL1 in T-cell acute lymphoblastic lymphoma/leukemia. Pathology - Research and Practice. 2019 02;215(2):265-271. https://doi.org/10.1016/j. prp.2018.10.021

21. Feucht J, Kayser S, Gorodezki D, Hamieh M, Döring M, Blaeschke F, Schlegel P, Bösmüller H, Quintanilla-Fend L, Ebinger M, Lang P, Handgretinger R, Feuchtinger T. T-cell responses against $\mathrm{CD} 19+$ pediatric acute lymphoblastic leukemia mediated by bispecific T-cell engager (BiTE) are regulated contrarily by PD-L1 and CD80/CD86 on leukemic blasts. Oncotarget. 201609 30;7(47):76902-76919. https:// doi.org/10.18632/oncotarget.12357

22. Inoue Y, Yoshimura K, Mori K, Kurabe N, Kahyo T, Mori $\mathrm{H}$, Kawase A, Tanahashi M, Ogawa H, Inui N, Funai K, Shinmura K, Niwa H, Suda T, Sugimura H. Clinical significance of PD-L1 and PD-L2 copy number gains in nonsmall-cell lung cancer. Oncotarget. 201604 01;7(22):3211332128. https://doi.org/10.18632/oncotarget.8528

23. Lawrence MS, Stojanov P, Polak P, Kryukov GV, Cibulskis K, Sivachenko A, Carter SL, Stewart C, Mermel CH, Roberts SA, Kiezun A, Hammerman PS, McKenna A, Drier Y, Zou L, Ramos AH, Pugh TJ, Stransky N, Helman E, Kim J, Sougnez C, Ambrogio L, Nickerson E, Shefler E, Cortés ML, Auclair D, Saksena G, Voet D, Noble M, DiCara D, Lin P, Lichtenstein L, Heiman DI, Fennell T, Imielinski M, Hernandez B, Hodis E, Baca S, Dulak AM, Lohr J, Landau D, Wu CJ, Melendez-Zajgla J, Hidalgo-Miranda A, Koren A, McCarroll SA, Mora J, Lee RS, Crompton B, Onofrio R, Parkin M, Winckler W, Ardlie K, Gabriel SB, Roberts CWM, Biegel JA, Stegmaier K, Bass AJ, Garraway LA, Meyerson M, Golub TR, Gordenin DA, Sunyaev S, Lander ES, Getz G. Mutational heterogeneity in cancer and the search for new cancer-associated genes. Nature. 201306 16;499(7457):214-218. https://doi.org/10.1038/nature12213

24. Patel SP, Kurzrock R. PD-L1 Expression as a Predictive Biomarker in Cancer Immunotherapy. Molecular Cancer Therapeutics. 201502 18;14(4):847-856. https://doi. org/10.1158/1535-7163.mct-14-0983

This work is licensed under a Creative Commons AttributionNon Commercial 4.0 International License. 